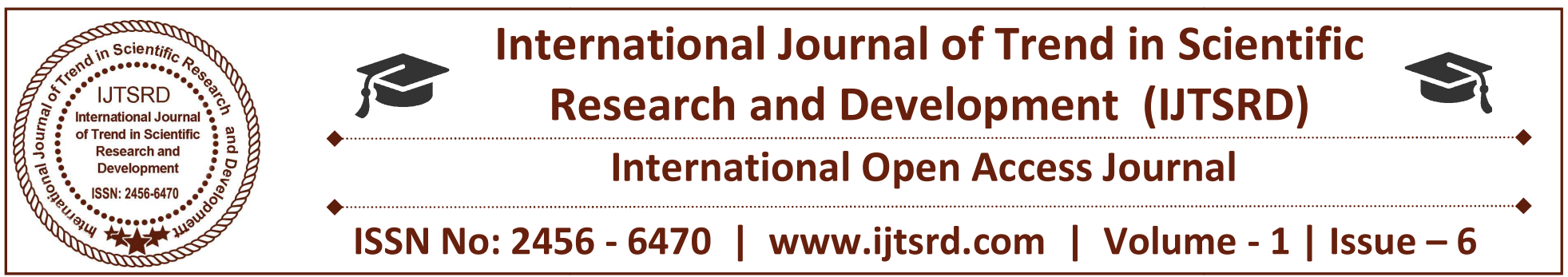

\title{
Bile Leakage during Laparoscopic Cholecystectomy A rare case of Aberrant Anatomy
}

\author{
Sumaira Nawaz Syed \\ Consultant Surgeon, Ramzaan Hospital, India
}

\begin{abstract}
Bile leakage in association with cholecystectomy is a well known complication. Common causes include damage to the biliary ducts and slipping of clips/ties. Here I describe a rare case of bile leakage which resulted due to aberrant biliary anatomy. A thirty four year old lady undergoing laparoscopic cholecystectomy developed bile leakage. It was not clear where the bile was leaking from. Therefore an intraoperative cholangiogram was performed. We found an accessory hepatic duct in the liver of this patient was draining separately from the rest of the biliary system. The laparoscopic operation had to be converted to open cholecystectomy in order to control the bile leakage. It can be concluded that the anatomy of the biliary tree is highly variable and the importance of intra operative cholangiograms during cholecystectomy should be emphasized.
\end{abstract}

Keywords: Laparoscopic $\quad$ Cholecystectomy
complications, Bile leakage.

\section{CASE PRESENTATION}

A thirty four year old caucasian lady with one year history of symptomatic gall stones was scheduled for elective cholecystectomy. Using the standard open technique, pneumoperitoneum was created and laparoscopic ports introduced; one $10 \mathrm{~mm}$ optical port through the umbilical area $10 \mathrm{~mm}$ telescope 30 degree, $10 \mathrm{~mm}$ operating port on the epigastria area, $5 \mathrm{~mm}$ operating port on the right hypochondrium, $5 \mathrm{~mm}$ operating port in the right iliac fossa.

After dissecting the gall bladder off the liver bed, bile was found to be leaking. No source was obvious. No duct injury had obviously occured. An intraoperative cholangiogram was performed therefore. An accessory hepatic duct was found draining a segment of the right lobe of liver. 


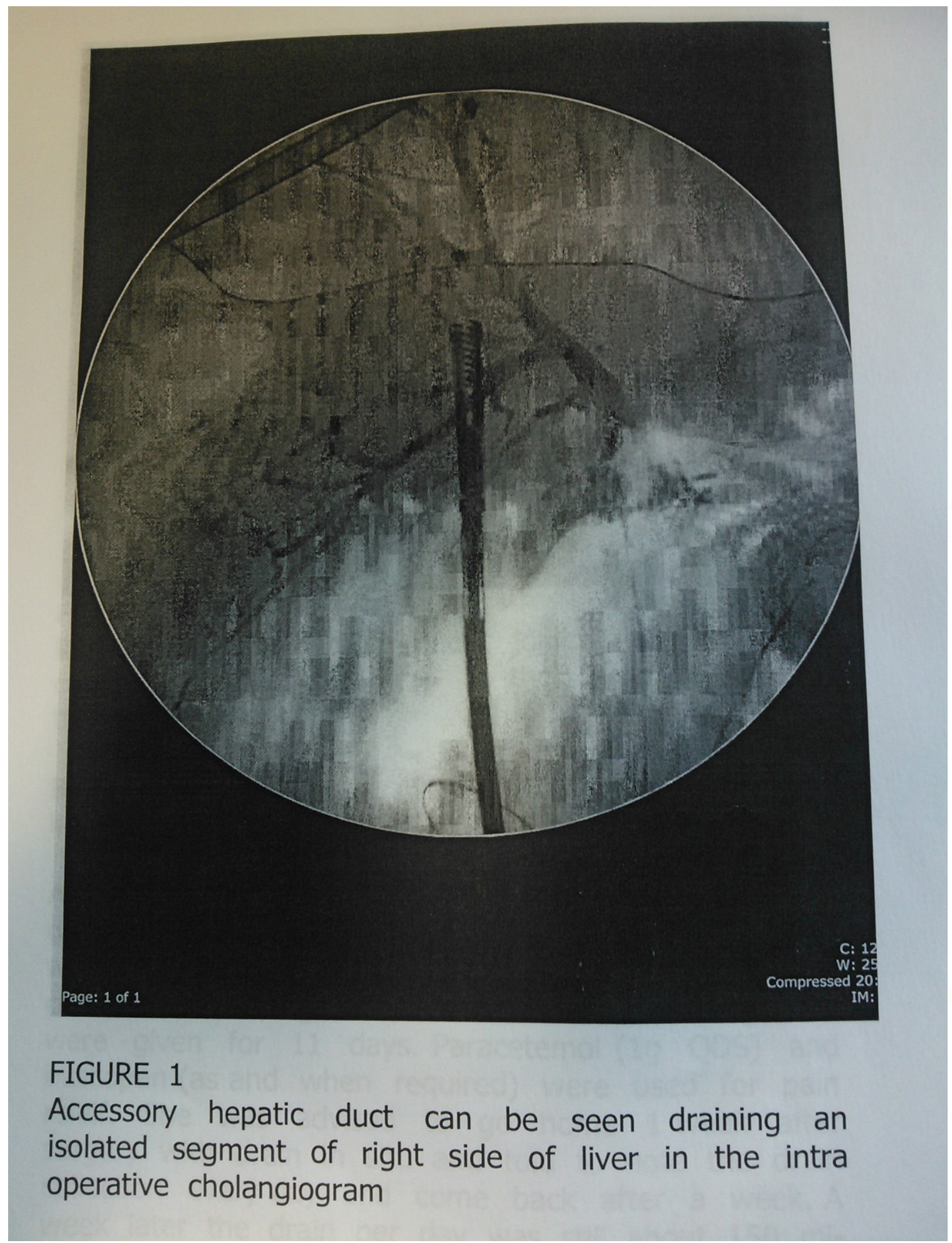

This segment [figure1] seemed to have a separate drainage from the rest of the hepatic biliary drainage system. 


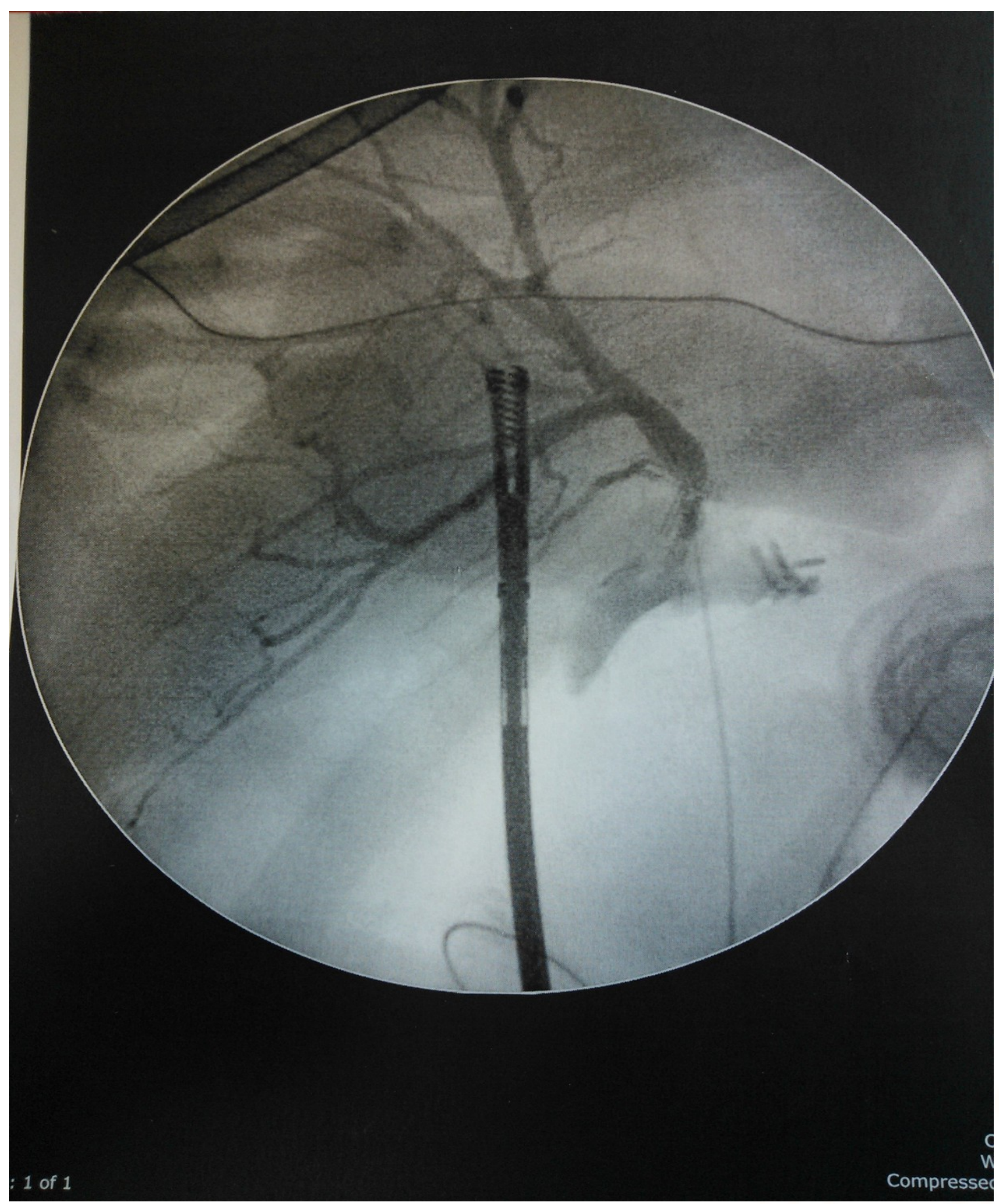

Due to continuous bile leakage from this segment, the operation had to be converted from laparoscopic to open cholecystectomy in order to control the bile leak. 


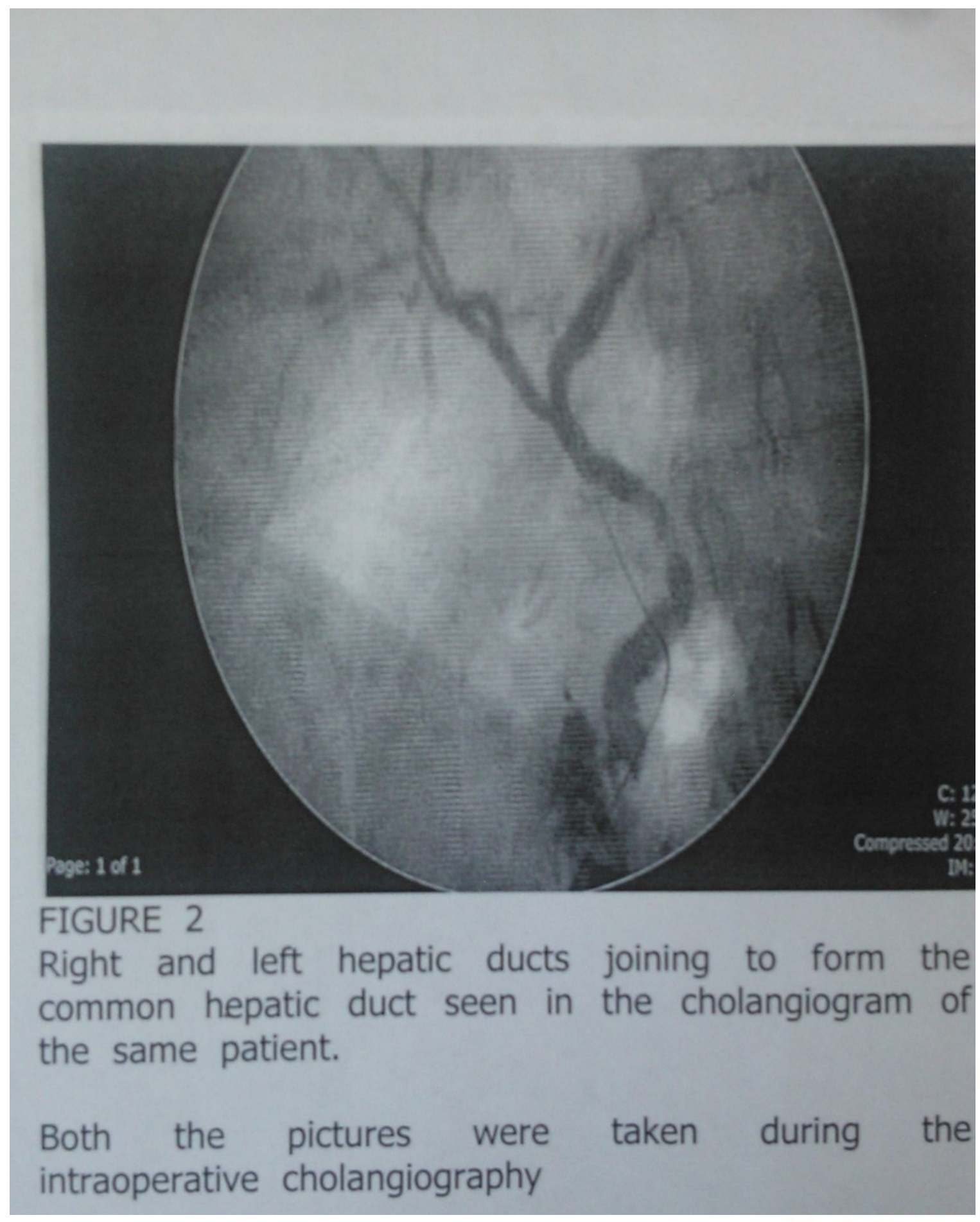

Bile leakage was controlled using clips and a drain was left in situ. The operation lasted for four and half hours. 


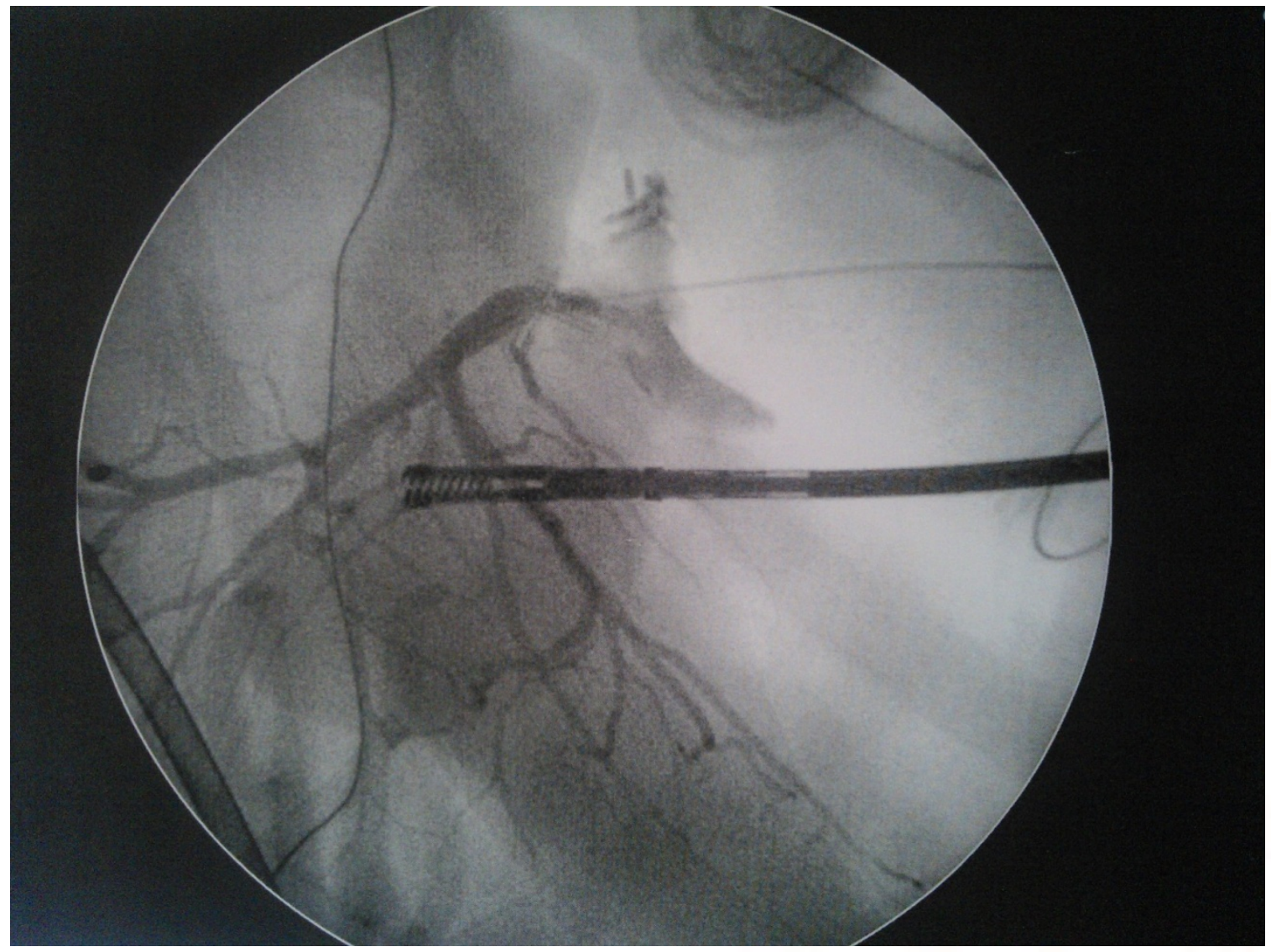

Post-operatively the output of bile in the drain was noted over 24 hour periods. Day 1 it was $230 \mathrm{ml}$, Day 2 it was $200 \mathrm{ml}$ and day 3 it was $138 \mathrm{ml}$. It seemed that the patients bile leak was reducing. However on day 4, it was $250 \mathrm{ml}$ and the patient developed increasing abdominal pain. It was crampy pain that radiated to her right shoulder and was associated with nausea and vomiting. On abdominal examination there was localized rigidity in the right abdominal pain. Investigations revealed a deranged liver function tests on day 4 postop with ALP $=384$ \& ALT $=140$ compared with the ALP $=200$ and $\mathrm{ALT}=91$ on day 1 postop. The pre operative figures were $\mathrm{ALP}=156$ and $\mathrm{ALT}=83$. The full blood counts, urea and electrolytes continued to be in normal range pre and post operatively

An ultrasound abdomen was requested. No obstruction to biliary drainage was evident on day 4 postop. Therefore it was decided to continue the patient management with analgesia antibiotics and wait and watch policy for the drain output. The drain output continued to be between 100-200 ml every 24 hours for the next one week. An MRCP was done. No evidence of biliary obstruction was there. We continued with the same management. Finally after 2 weeks the drain amount became less than $50 \mathrm{ml} / 24$ hr.s. Drain was thus removed 4 weeks post operatively when the amount in the drain was 10 $\mathrm{ml} / 24 \mathrm{hrs}$ and the patient sent home.

\section{DISCUSSION}

According to Couinaud classification there are eight distinct hepatic segments in a liver having normal anatomy. There are also some well known variants in the anatomy of biliary tree. The variations in the fusion of the right posterior hepatic duct with the right anterior hepatic duct or left hepatic duct are the most common. The most common variation reported to occur in the anatomy of the biliary tree found in $13 \%$ $19 \%$ of the population is the drainage of the right posterior duct into the left hepatic duct without confluencing with the right anterior duct. In $11 \%$ of the population the variation called triple confluence is found which means that the right posterior duct, right anterior duct and left hepatic duct empty simultaneously into the common hepatic duct. Variation in the cystic duct anomaly include a low cystic duct insertion [when the cystic duct fuses with the distal third of the extra hepatic bile duct] found in $9 \%$ people, a medial cystic duct insertion [when the cystic duct fuses and drains into the left side of the common hepatic duct] found in upto $17 \%$ of the 
people and a parallel course of cystic duct and common hepatic duct over at least $2 \mathrm{~cm}$ segment [can be found in up to $25 \%$ people [1].There are also some variants in the biliary tree anatomy which are less commonly known. These include presence of accessory hepatic ducts alongside the normal right and left hepatic duct systems draining ultimately into the main system, an accessory right posterior duct draining into the cystic duct or an aberrant insertion of the cystic duct into with the right or left hepatic duct[1]. There are also small ducts arising from the right hepatic lobe called ducts of Luschka or subvesical ducts which course along the gall bladder fossa and drain into the extrahepatic bile duct system usually[2]. An aberrant hepatic duct called cystohepatic duct is found frequently travelling across the calots triangle [3].

This case report is unique as the accessory hepatic duct found as the cause of bile leak did not drain into the main biliary tree. It drained a segment of the liver separate from the main hepatic duct system. The bile leakage from this duct could be visualized only by intra operative cholangiogram and no ducts of Luschka could be identified. There was no cystohepatic duct. The accessory hepatic duct caused the bile leakage intraoperatively and also postoperatively.

\section{CONCLUSION}

The anatomy of biliary tree can be highly variable in normal subjects also. Accessory bile ducts can cause bile leak not only intraoperatively but also postoperatively for prolonged periods. The bile leakage from accessory bile ducts can be identified by intraoperative cholangiograms only. Therefore in all cases of laparoscopic cholecystectomies, use of intraoperative cholangiograms must be emphasized to identify the source of bile leakage.

Postoperative bile leakage can be managed conservatively if the amount of bile leak is less than $250 \mathrm{ml} / 24 \mathrm{hrs}$ although it might take weeks to settle.

\section{REFERENCES}

1) Koenraad J. Mortelé1,2 and Pablo R. Ros3 Anatomic Variants of the Biliary Tree: MR Cholangiographic Findings and Clinical Applications AJR August 2001 vol. 177 no.2 389394

2) Constantine P. Spanos, Theodore Syrakos Bile leaks from the duct of Luschka (subvesical duct): a

review

Langenbeck's Archives of Surgery ,September 2006, Volume 391, Issue 5, pp 441-447

3) Taku Aoki1, Hiroshi Imamura1, Yoshihiro Sakamoto1, Kiyoshi Hasegawa1, Yasuji Seyama1, Keiichi Kubota2 and Masatoshi Makuuchi1 Bile Duct of Luschka Connecting with the Cystohepatic Duct: The Importance of Cholangiography During Surgery American Journal of Roentgenology $>$ Volume 180 , Issue 3 